\title{
STATISTICAL OPTIMIZATION OF WIRE-EDM DURING PROCESSING OF HYBRID MMC
}

\section{ASHISH KUMAR SRIVASTAVA}

GL BAJAJ Institute of Technology and Management, Greater Noida, GB Nagar, India

\begin{abstract}
High tool wear rate and high cycle time in conventional machining have provided a dreadful response for harder materials and it is also very difficult to machine the complex shapes by such machines. Wire Electric Discharge Machining (WEDM) is widely used non-conventional machining for the hard materials and intricate shapes. In this paper, an attempt is made to investigate the surface integrity of the machine surface as well as the performance of the hybrid $M M C A 359 / \mathrm{Al}_{2} \mathrm{O}_{3} / \mathrm{B}_{4} \mathrm{C}$ during the wire-EDM process under different operating conditions. SEM analysis has been carried out to analyze the machined surface. The output response is measured in terms of surface roughness and MRR. The analysis part has been done by using the $L_{27}$ Taguchi's array under the randomly designed experiment trials. At the end of the result, grey relation analysis has been made as a confirmation attempt to compare the performance effectiveness of the proposed method.
\end{abstract}

KEYWORDS: Hybrid Metal Matrix Composite, Electromagnetic Stir Casting, Wire EDM, Residual Stresses \& Microhardness

Received: Sep 22, 2018; Accepted: Oct 13, 2018; Published: Dec 15, 2018; Paper Id.: IJMPERDDEC201879

\section{INTRODUCTION}

Composites are formed by combining two or more materials ensure performance advantages and facilitate multiple functionalities, which cannot be expected from the traditional materials [1]. Metal matrix composites (MMCs) are one of it. Their upgraded characteristics, such as high strength to weight ratio, improved mechanical properties, and light weight etc., make them the best suitable advanced materials [2]. While using MMCs, reinforcing materials have to be embedded into a metallic matrix by melting the matrix material [3]. As compared to other known materials, these composites possess high wear resistance, high tensile and compressive strengths, structural effectiveness, thermophysical and mechanical properties, making them suitable for many important engineering jobs [4]. Two or more reinforced materials have to be added to the matrix metal in the essential amount to make the hybrid MMCs [5]. However, MMCs are not widely used in the industries because of their poor machinability [6]. In composite materials like MMCs, machinability is a very difficult process due to the high tool wear. It occurs due to the presence of hard abrasive particles (reinforcements), which result in increased cost of machining. Non-conventional machining method like wire electric discharge machining (wire-EDM) provides excellent properties of machining as compared to the traditional methods [7]. In this method, a molybdenum or brass thin wire is fed into the work sample which is sunk in the tank filled with dielectric fluid, such as, demineralized water. The major advantage of this process is that it cuts plates with up to $350 \mathrm{~mm}$ thickness and gives better accuracy in making of tools, dies, and punches. 
The primary objective of the wire-EDM machining is to improve the performance of the output in terms of material removal rate, surface roughness, surface integrity, and dimension accuracy. However, optimum machining parameters and cost-effective machining are still the core area for the researchers along with that of reliability and reproducibility of the machining process. Other non-conventional machining processes such as abrasive waterjet also applicable to hard materials. However, the dimensional accuracy is one of the major drawback [8, 9]. F Muller and $\mathbf{J}$ Monaghan[10]has optimized the parametric combinations in wire-EDM. The non-dominated point concept was introduced in selecting the best combination of parameters. Mahapatra SS and Patnaik A [11] have optimized the wire-EDM process parameters using the Taguchi method. In this method, at the end of the analysis, a genetic algorithm is used to get the multi-objective parametric optimization of the machining process. Machining of DC-53 steel by wire-EDM and analysis of the surface roughness has been reported by Kanlayasiri K and Boonmung S [12]. Boujelbene M et al [13] have reported the analysis of surface integrity in electrical discharge machining on 50CrV4 and X200Cr15 steel. Their work has analyzed the thickness of the white layer, electrode wear ratio (EWR), metal removal rate (MRR) and the microhardness. An abrasive mixed electrical discharge machining and multi-level optimization of its machining parameters by orthogonal array and grey relational analysis have been done by Kumar Anil et al [14]. Kumar K and Agarwal S [15] have presented their work on multi-objective optimization of the wire-EDM machining parameters. Jabbaripour B. et al [16] investigating the results of EDM machining of Ti-6Al-4V and its parameters on surface properties, TWR and MRR. The chemical elements and compounds over the surface of the workpiece after machining was examined by EDS and XRD analyses. Sudhakara Det al [17] have made an experimental study of EDM machining of Inconel-718. Garg HK et al [18] have discussed the machining of hybrid MMC of aluminum (Al/SiC/Gr and Al/Si10Mg/Fly ash/Gr). The Multi-objective optimization using non-dominating sorting genetic algorithm-II of machining parameters of EDM has been reported by Baraskar S. S. et al [19]. Srivastava AK et al [2] has studied the process parameters of wire EDM during machining of the Al2024/SiC composite. In his study, the effect of input parameters on machining outcomes such as MRR and surface roughness was evaluated. Srivastava AK et al [5] has reviewed the effect of conventional and non-conventional machining processes on hard materials like MMCs. They also discuss the limitations and merits of different machining processes in the processing of MMCs. Srivastava AK et al [20] has studied the wire EDM process parameters on turning of hybrid MMC. In his study, a fixture is used for turning motion and the rotational speed of workpiece sample was taken into study. Srivastava AK [21] has compared the elements of surface integrity in procession via two non-conventional machining processes namely abrasive waterjet and wire EDM.

In this work, The analysis part has been done by using the $\mathrm{L}_{27}$ Taguchi's array under the randomly designed experiment trials. At the end of the result, grey relation analysis has been made as a confirmation attempt to compare the performance effectiveness of the proposed method.

\section{EXPERIMENTAL PROCEDURE}

The experimental work started with a selection of materials. In this work, A359 aluminum alloy is used as a base metal. A359 has good casting and wettability properties. $\mathrm{B}_{4} \mathrm{C}$ and $\mathrm{Al}_{2} \mathrm{O}_{3}$ are used as the reinforcement material. The composition, thermal and physical properties of used materials was reported in our other published work [22]. A mechanical stirring process was applied to produce the hybrid MMCs. Maxicut 4 axis CNC WEDM machine of Electronica Corporation is used for machining of fabricated MMCs, as shown in figure 1(a). This machine has the flexibility to choose machining parameters as per the requirement of the selected materials. Molybdenum wire of diameter 
$0.18 \mathrm{~mm}$ and demineralized water as a working fluid was used in the experiment as fixed parameters. The photographic view of machine zone is shown in figure 1(b). The main input variable parameters of the machine were peak current (A), pulse on-time $\left(\mathrm{T}_{o n}\right)(\mathrm{B})$, pulse off-time $\left(\mathrm{T}_{o f f}\right)(\mathrm{C})$ and wire feed $(\mathrm{D})$, which were selected at three different levels on the basis of their range availability. The set of design levels is shown in table 1.

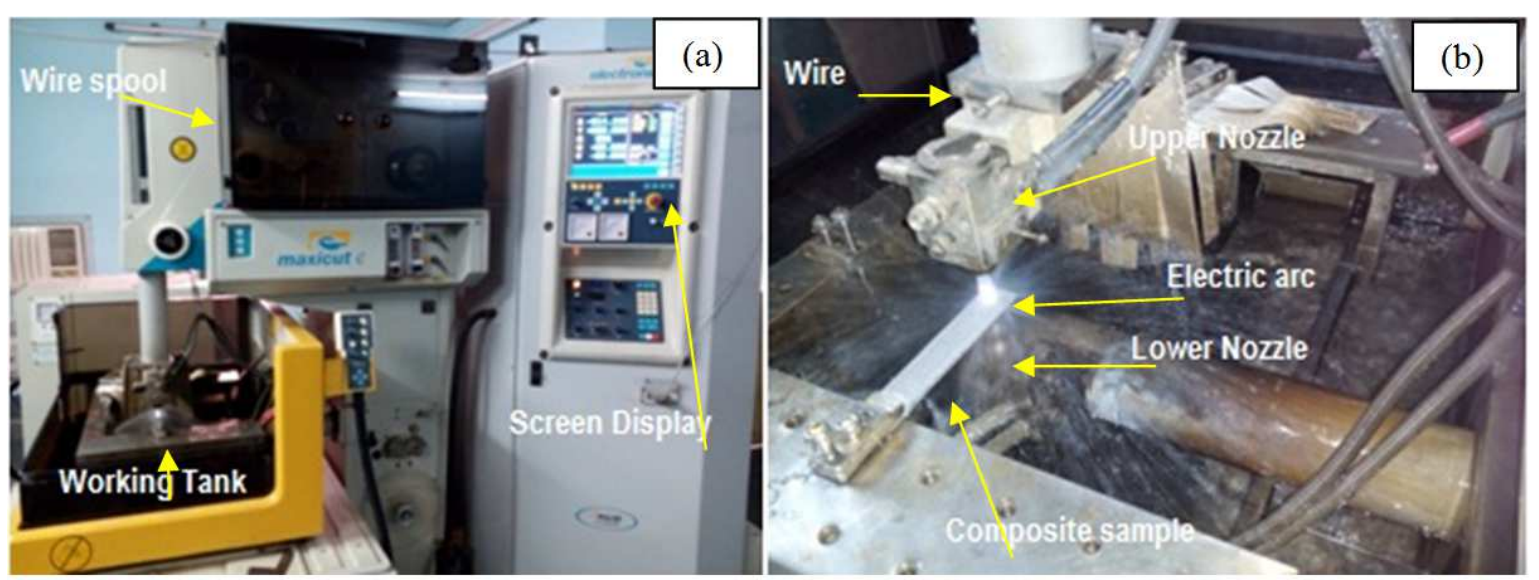

Figure 1(a) Wire EDM Machine and (b) Machining Zone

Table 1: Input Parameters and Level of Design

\begin{tabular}{|c|c|c|c|c|}
\hline Factor & Peak Current & Pulse on Time & Pulse off Time & Wire Feed \\
\hline Unit & $\mathrm{Amp}$ & $\mu \mathrm{S}$ & $\mu \mathrm{S}$ & $\mathrm{m} / \mathrm{min}$ \\
\hline Symbol & $\mathrm{A}$ & $\mathrm{B}$ & $\mathrm{C}$ & $\mathrm{D}$ \\
\hline L1 & 2 & 15 & 3 & 8 \\
\hline L2 & 3 & 20 & 4 & 8.5 \\
\hline L3 & 4 & 25 & 5 & 9 \\
\hline
\end{tabular}

Two output parameters, namely, surface roughness and MRR, which were analyzed after the machining of fabricated samples. Surface roughness was deliberated by surface roughness tester. Material removal rate was measured by using equation (1).

Metal removal rate $=\mathrm{V}_{\mathrm{c}} \mathrm{x}$ b $\mathrm{x}$

Where $\mathbf{V}_{\mathbf{c}}=$ cutting velocity, $\mathbf{b}=$ width of kerf (width of cut) and $\mathbf{t}=$ plate thickness.

Cutting speed was calculated by measuring time to complete the cut. The kerf width was obtained by a microscope. In this work, the Taguchi technique was applied to find optimum process parameters. $\mathrm{L}_{27}$ array, $\mathrm{S} / \mathrm{N}$ ratio and analysis of variance (ANOVA) were applied to study the performance characteristics of the machining parameters. The $\mathrm{S} / \mathrm{N}$ ratio can be calculated as a logarithmic transformation of the function as shown in equations 2 and 3, below. Optimum performance characteristics for MRR are 'the larger the better', and for surface roughness, 'the smaller the better' respectively.

$$
\begin{aligned}
& \frac{S}{N} \text { ratioforMRR }=-10 \log \log _{10}{ }_{n}^{1} \Sigma\left(\frac{1}{y^{2}}\right) \\
& \frac{S}{N} \text { ratiofor } R a=-10 \log \log _{10}{ }_{n}^{1} \Sigma\left(y^{2}\right)
\end{aligned}
$$




\section{RESULT AND DISCUSSIONS}

The SEM images of machined samples were taken to analyses the micro study of the surface. The typical SEM images of the machined sample at three different places are shown in figure 2(a,b, c). The figures indicate that hard particles, which did not melt during the machining, formed the craters and voids which increased the surface roughness. Porosity is also seen on the surface due to the evaporation process and the explosion of gas bubbles.
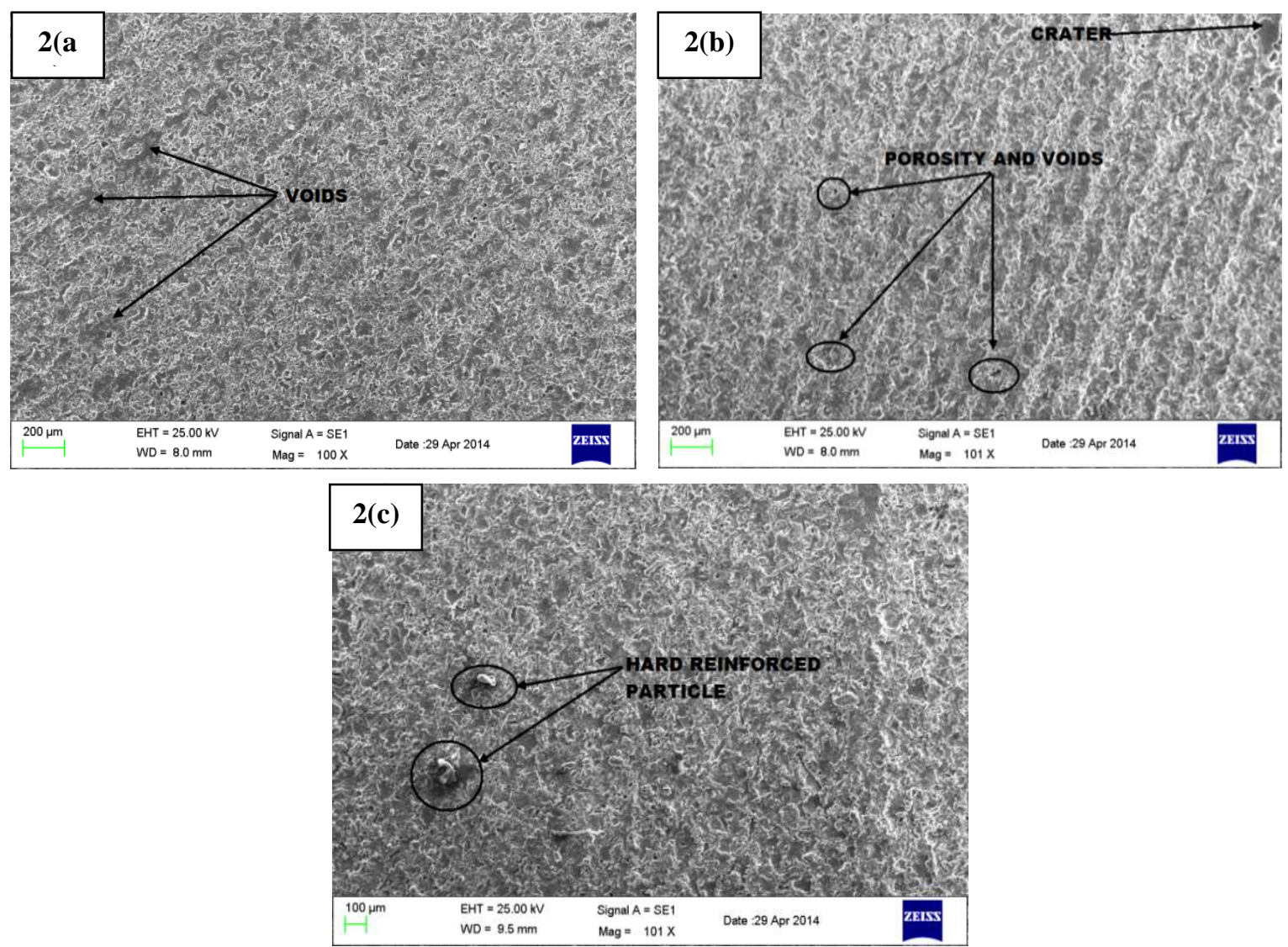

Figure 2 (a, b, c): Typical SEM Images of Machined Sample A359 +2\% $\mathrm{Al}_{2} \mathrm{O}_{3}+2 \% \mathrm{~B}_{4} \mathrm{C}$

The analysis of the experiment was done by using Minitab-17 software which is used for designing experiment applications. An $\mathrm{L}_{27}$ array of the Taguchi's design is shown in table 2. The output response of the experiment was transformed in $\mathrm{S} / \mathrm{N}$ ratio for measuring the performance characteristic of the input machining variables. Mean signal to noise ratio graph for the two output parameters are shown in figure3 $(a, b)$ respectively. Figure 3(a) indicates that the roughness of the surface increased with an increase of peak current. This was due to the melting of materials at high discharge energy. At high discharge energy, some of the surface particles which are not melted are removed like a brittle fracture or in the dimple nature, which creates voids at the surface. Another reason is the hard abrasive particles $\mathrm{B}_{4} \mathrm{C}$ and $\mathrm{Al}_{2} \mathrm{O}_{3}$. These hard particles did not melt during the machining. Hence, the molten metal turned viscous resulting in a rough surface and slow removal of metals. Figure 3(b) indicates that with an increase in the peak current, metal removal rate also increased. On the other hand, the surface became rough because when the peak current increased, the discharge of heat energy increased as well. This helped in the removal of more metals. However, due to the discharge of heat energy, the molten metal at the surface started evaporating and formed gas bubbles which exploded and made the surface roughness due to the creation of voids. On the basis of parametric optimized conditions, the corresponding values of input parameters 
are shown in Table 3. Table 4 shows the results of the ANOVA table for surface roughness and MRR respectively. Considering the sum of square values, it was estimated that the peak current was a major factor which contributed $70.02 \%$ to the better surface finish, however, pulse on-time $\left(\mathrm{T}_{\text {on }}\right)$ contributed $22.48 \%$.

Table 2: Experimental Design using $\mathrm{L}_{27}$ Orthogonal Array

\begin{tabular}{|c|c|c|c|c|c|c|c|c|c|}
\hline \multirow[b]{2}{*}{ Std } & \multirow[b]{2}{*}{ Run } & \multicolumn{4}{|c|}{ Input Parameters } & \multicolumn{2}{|c|}{ Output Response } & \multicolumn{2}{|c|}{ S/N Ratio of Response } \\
\hline & & A & B & $\mathrm{C}$ & $\mathrm{D}$ & $\begin{array}{c}\text { Surface } \\
\text { Roughness (Ra) }\end{array}$ & $\begin{array}{c}\text { MRR } \\
(\mathrm{mm} / \mathrm{min})\end{array}$ & $\begin{array}{l}\text { S/n } \\
\text { Ra }\end{array}$ & $\begin{array}{c}\text { S/n } \\
\text { MRR }\end{array}$ \\
\hline 11 & 1 & 2 & 1 & 3 & 2 & 2.5483 & 1.424 & -8.125 & 3.070 \\
\hline 21 & 2 & 3 & 1 & 2 & 3 & 2.7846 & 1.4686 & -8.895 & 3.338 \\
\hline 9 & 3 & 1 & 3 & 3 & 3 & 2.544 & 1.2758 & -8.110 & 2.116 \\
\hline 23 & 4 & 3 & 2 & 3 & 2 & 2.898 & 1.5574 & -9.242 & 3.848 \\
\hline 15 & 5 & 2 & 2 & 1 & 3 & 2.734 & 1.3225 & -8.736 & 2.428 \\
\hline 13 & 6 & 2 & 2 & 1 & 1 & 2.722 & 1.3927 & -8.698 & 2.877 \\
\hline 18 & 7 & 2 & 3 & 2 & 3 & 2.537 & 1.409 & -8.086 & 2.978 \\
\hline 20 & 8 & 3 & 1 & 2 & 2 & 2.8193 & 1.4398 & -9.003 & 3.166 \\
\hline 26 & 9 & 3 & 3 & 1 & 2 & 3.1317 & 1.6476 & -9.916 & 4.337 \\
\hline 27 & 10 & 3 & 3 & 1 & 3 & 3.0821 & 1.6135 & -9.777 & 4.155 \\
\hline 16 & 11 & 2 & 3 & 2 & 1 & 2.559 & 1.452 & -8.161 & 3.239 \\
\hline 6 & 12 & 1 & 2 & 2 & 3 & 2.423 & 1.3585 & -7.687 & 2.661 \\
\hline 2 & 13 & 1 & 1 & 1 & 2 & 2.2637 & 1.212 & -7.096 & 1.670 \\
\hline 24 & 14 & 3 & 2 & 3 & 3 & 2.787 & 1.5146 & -8.903 & 3.606 \\
\hline 12 & 15 & 2 & 1 & 3 & 3 & 2.4997 & 1.395 & -7.958 & 2.891 \\
\hline 10 & 16 & 2 & 1 & 3 & 1 & 2.5868 & 1.465 & -8.255 & 3.317 \\
\hline 25 & 17 & 3 & 3 & 1 & 1 & 3.1146 & 1.6787 & -9.868 & 4.499 \\
\hline 14 & 18 & 2 & 2 & 1 & 2 & 2.843 & 1.3612 & -9.076 & 2.678 \\
\hline 17 & 19 & 2 & 3 & 2 & 2 & 2.576 & 1.426 & -8.219 & 3.082 \\
\hline 19 & 20 & 3 & 1 & 2 & 1 & 2.8021 & 1.4095 & -8.950 & 2.981 \\
\hline 8 & 21 & 1 & 3 & 3 & 2 & 2.586 & 1.2994 & -8.253 & 2.275 \\
\hline 22 & 22 & 3 & 2 & 3 & 1 & 2.846 & 1.4993 & -9.085 & 3.518 \\
\hline 4 & 23 & 1 & 2 & 2 & 1 & 2.408 & 1.3812 & -7.633 & 2.805 \\
\hline 5 & 24 & 1 & 2 & 2 & 2 & 2.469 & 1.3658 & -7.850 & 2.708 \\
\hline 1 & 25 & 1 & 1 & 1 & 1 & 2.2232 & 1.2532 & -6.940 & 1.960 \\
\hline 7 & 26 & 1 & 3 & 3 & 1 & 2.538 & 1.3186 & -8.090 & 2.402 \\
\hline 3 & 27 & 1 & 1 & 1 & 3 & 2.2374 & 1.1987 & -6.995 & 1.574 \\
\hline
\end{tabular}
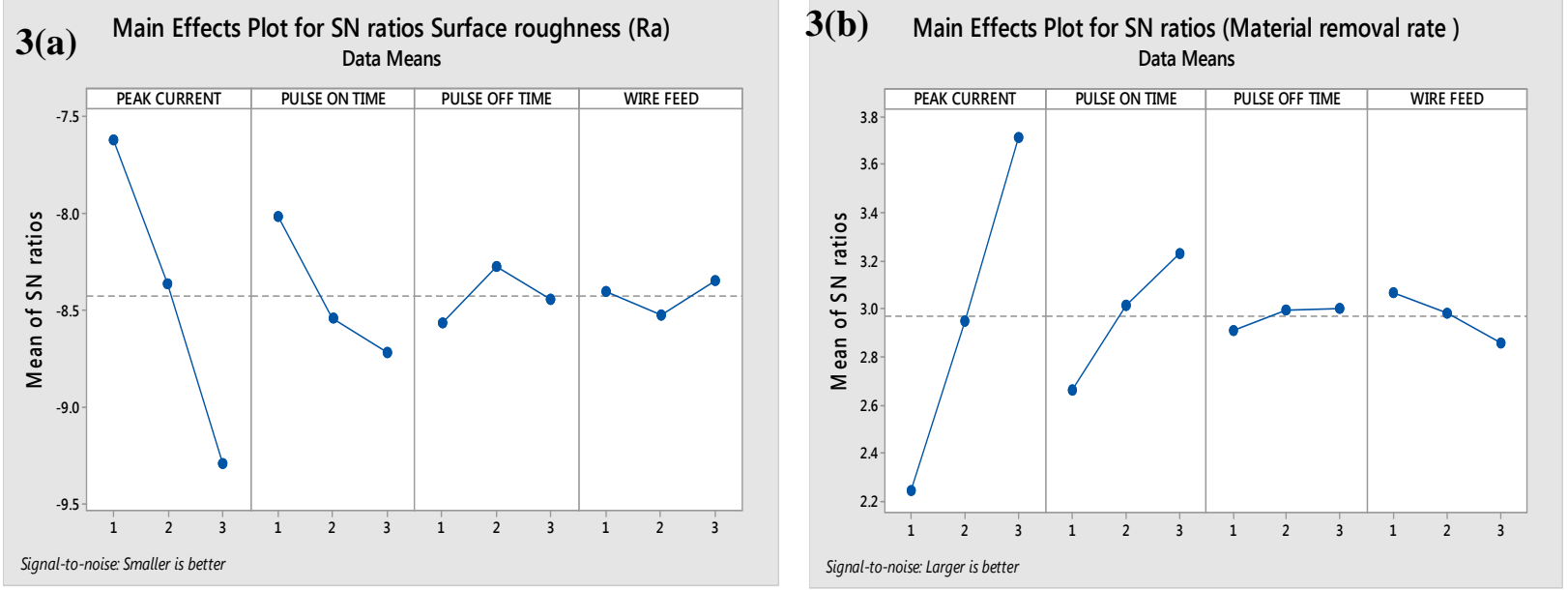

Figure 3(a, b): S/N Ratio Graph for Surface Roughness and Metal Removal Rate 
Table 3: Optimized Combination Values of Input Parameters Obtained from Taguchi's Array

\begin{tabular}{|c|c|c|c|c|}
\hline \multirow{2}{*}{$\begin{array}{c}\text { Output } \\
\text { Parameters }\end{array}$} & \multicolumn{4}{|c|}{ Variable Input Parameters } \\
\cline { 2 - 5 } & $\mathbf{A}($ Peak Current) & $\mathbf{B}_{\left(\mathbf{T}_{\text {ON }}\right)}$ & $\mathbf{C}_{\left(\mathbf{T}_{\text {OFF }}\right)}$ & D(Wire feed \\
\hline Surface Roughness & $\mathrm{A}_{1}=2$ & $\mathrm{~B}_{1}=15$ & $\mathrm{C}_{2}=4$ & $\mathrm{D}_{3}=9$ \\
\hline MRR & $\mathrm{A}_{3}=4$ & $\mathrm{~B}_{3}=25$ & $\mathrm{C}_{3}=5$ & $\mathrm{D}_{1}=8$ \\
\hline
\end{tabular}

Table 4: ANOVA Table for the Output Response

\begin{tabular}{|l|c|c|c|c|c|}
\hline \multicolumn{1}{|c|}{ Parameter } & $\begin{array}{c}\text { Sum of } \\
\text { Squares }\end{array}$ & $\begin{array}{c}\text { Degree of } \\
\text { Freedom }\end{array}$ & $\begin{array}{c}\text { Mean } \\
\text { Square }\end{array}$ & F Value & $\begin{array}{c}\text { \% } \\
\text { Contribution }\end{array}$ \\
\hline A-Peak Current & 12.05 & 2 & 6.03 & 724.38 & 70.02 \\
\hline B-Pulse On-time & 3.87 & 2 & 1.93 & 232.59 & 22.48 \\
\hline C-Pulse OFF-Time & 0.33 & 2 & 0.17 & 20.1 & 1.94 \\
\hline D-Wire Feed & 0.14 & 2 & 0.07 & 8.06 & 0.79 \\
\hline Error & 0.82 & 16 & 0.01 & & 4.77 \\
\hline Total & $\mathbf{1 7 . 2 1}$ & $\mathbf{2 6}$ & & & $\mathbf{1 0 0}$ \\
\hline \multicolumn{7}{|c|}{ Metal Removal Rate } & 4.76 & 204.28 & 66.76 \\
\hline A-Peak Current & 9.52 & 2 & 0.71 & 30.34 & 9.89 \\
\hline B-Pulse On-time & 1.41 & 2 & 1.16 & 49.9 & 16.27 \\
\hline C-Pulse OFF-Time & 2.32 & 2 & 0.08 & 3.62 & 1.2 \\
\hline D-Wire Feed & 0.17 & 2 & 0.02 & & 5.88 \\
\hline Error & 0.84 & 16 & & & $\mathbf{1 0 0}$ \\
\hline Total & $\mathbf{1 4 . 2 6}$ & $\mathbf{2 6}$ & & \\
\hline
\end{tabular}

A contribution of pulse off-time $\left(\mathrm{T}_{\mathrm{off}}\right)$ and wire feed was $1.94 \%$ and $0.79 \%$, respectively which indicates that the effect of these two parameters was less significant compared to the other parameters. A $4.77 \%$ of error was also found due to the unavoidable factors like fixed parameters. The most significant factor resulting in maximum metal removal rate was the peak current whose contribution was $66.76 \%$. Other important parameters were pulsed off- time ( $\left.\mathrm{T}_{\text {off }}\right)$ and pulse ontime $\left(\mathrm{T}_{\mathrm{o}}\right)$, contributing $16.27 \%$ and $9.89 \%$, respectively. A contribution of wire feed was $0.43 \%$, which indicates as less significant parameter. Total error calculated was $5.88 \%$. The R-Squared values calculated for surface roughness and metal removal rate were 0.9923 and 0.9738 respectively which confirms the accuracy of the intended constants and fitness of the developed model. A confirmation experiment was done to verify the effect of the optimized combination of machining parameters on the output response. It also verified the reproducibility of the set of optimized input parameters. Experiments were carried out as per the set of input parameters shown in table 4. The results obtained for the optimized machining parameters are shown in table 5. It indicates that the optimized value of the surface roughness was $2.18 \mu \mathrm{m}$ and metal removal rate was $1.654 \mathrm{~mm} / \mathrm{min}$.

Grey relation analysis was also done to find the optimized combination of parameters when and where only partial information was available. According to the grey relation analysis, all the available information is white information, all the unavailable information is black information and all the partially available information is called grey information.

Table 5: Results of Confirmation Experiment for Optimized Machining Parameters

\begin{tabular}{|c|c|c|c|c|c|c|}
\hline Response & $\begin{array}{c}\text { Input } \\
\text { Parameters }\end{array}$ & $\begin{array}{c}\text { A } \\
\text { Peak Current }\end{array}$ & $\begin{array}{c}\mathbf{B} \\
\mathbf{T}_{\text {ON }}\end{array}$ & $\begin{array}{c}\mathbf{C} \\
\mathbf{T}_{\text {OFF }}\end{array}$ & $\begin{array}{c}\text { D } \\
\text { Wire feed }\end{array}$ & $\begin{array}{c}\text { Output } \\
\text { Response }\end{array}$ \\
\hline Surface Roughness $(\mu \mathrm{m})$ & Level & $\mathrm{A}_{1}=2$ & $\mathrm{~B}_{1}=15$ & $\mathrm{C}_{2}=4$ & $\mathrm{D}_{3}=9$ & 2.18 \\
\hline MRR $(\mathrm{mm} / \mathrm{min})$ & Level & $\mathrm{A}_{3}=4$ & $\mathrm{~B}_{3}=25$ & $\mathrm{C}_{3}=5$ & $\mathrm{D}_{1}=8$ & 1.654 \\
\hline
\end{tabular}


Table 6: Grey Relation Analysis

\begin{tabular}{|c|c|c|c|c|c|c|c|c|c|c|}
\hline \multirow{2}{*}{ Std } & \multirow{2}{*}{ Run } & \multicolumn{6}{|c|}{ Input Parameters } & \multicolumn{2}{c|}{$\begin{array}{c}\text { Grey Relation } \\
\text { Data Generation }\end{array}$} & \multicolumn{2}{c|}{$\begin{array}{c}\text { Grey Relation } \\
\text { Coefficient }\end{array}$} & \multirow{2}{*}{$\begin{array}{c}\text { Grey Relation } \\
\text { Grade }\end{array}$} \\
\cline { 4 - 10 } & & A & B & C & D & S.R & MRR & S.R & MRR & \\
\hline 11 & 1 & 2 & 1 & 3 & 2 & 0.672 & 0.469 & 0.427 & 0.516 & 0.449 \\
\hline 21 & 2 & 3 & 1 & 2 & 3 & 0.4 & 0.562 & 0.556 & 0.471 & 0.4506 \\
\hline 9 & 3 & 1 & 3 & 3 & 3 & 0.677 & 0.161 & 0.425 & 0.757 & 0.5881 \\
\hline 23 & 4 & 3 & 2 & 3 & 2 & 0.269 & 0.747 & 0.65 & 0.401 & 0.5258 \\
\hline 15 & 5 & 2 & 2 & 1 & 3 & 0.458 & 0.258 & 0.522 & 0.66 & 0.5512 \\
\hline 13 & 6 & 2 & 2 & 1 & 1 & 0.472 & 0.404 & 0.514 & 0.553 & 0.5014 \\
\hline 18 & 7 & 2 & 3 & 2 & 3 & 0.685 & 0.438 & 0.422 & 0.533 & 0.5356 \\
\hline 20 & 8 & 3 & 1 & 2 & 2 & 0.36 & 0.502 & 0.581 & 0.499 & 0.4746 \\
\hline 26 & 9 & 3 & 3 & 1 & 2 & 0 & 0.935 & 1 & 0.348 & 0.6297 \\
\hline 27 & 10 & 3 & 3 & 1 & 3 & 0.057 & 0.864 & 0.897 & 0.367 & 0.5885 \\
\hline 16 & 11 & 2 & 3 & 2 & 1 & 0.66 & 0.528 & 0.431 & 0.487 & 0.5374 \\
\hline 6 & 12 & 1 & 2 & 2 & 3 & 0.816 & 0.333 & 0.38 & 0.6 & 0.542 \\
\hline 2 & 13 & 1 & 1 & 1 & 2 & 1 & 0.028 & 0.333 & 0.947 & 0.7603 \\
\hline 24 & 14 & 3 & 2 & 3 & 3 & 0.397 & 0.658 & 0.557 & 0.432 & 0.5496 \\
\hline 12 & 15 & 2 & 1 & 3 & 3 & 0.728 & 0.409 & 0.407 & 0.55 & 0.4615 \\
\hline 10 & 16 & 2 & 1 & 3 & 1 & 0.628 & 0.555 & 0.443 & 0.474 & 0.4357 \\
\hline 25 & 17 & 3 & 3 & 1 & 1 & 0.02 & 1 & 0.962 & 0.333 & 0.6521 \\
\hline 14 & 18 & 2 & 2 & 1 & 2 & 0.333 & 0.339 & 0.601 & 0.596 & 0.5302 \\
\hline 17 & 19 & 2 & 3 & 2 & 2 & 0.64 & 0.474 & 0.439 & 0.514 & 0.5631 \\
\hline 19 & 20 & 3 & 1 & 2 & 1 & 0.38 & 0.439 & 0.568 & 0.532 & 0.478 \\
\hline 8 & 21 & 1 & 3 & 3 & 2 & 0.629 & 0.21 & 0.443 & 0.704 & 0.542 \\
\hline 22 & 22 & 3 & 2 & 3 & 1 & 0.329 & 0.626 & 0.603 & 0.444 & 0.5194 \\
\hline 4 & 23 & 1 & 2 & 2 & 1 & 0.834 & 0.38 & 0.375 & 0.568 & 0.4738 \\
\hline 5 & 24 & 1 & 2 & 2 & 2 & 0.763 & 0.348 & 0.396 & 0.59 & 0.4784 \\
\hline 1 & 25 & 1 & 1 & 1 & 1 & 1.047 & 0.114 & 0.323 & 0.815 & 0.9083 \\
\hline 7 & 26 & 1 & 3 & 3 & 1 & 0.684 & 0.25 & 0.422 & 0.667 & 0.5484 \\
\hline 3 & 27 & 1 & 1 & 1 & 3 & 1.03 & 0 & 0.327 & 1 & 0.7633 \\
\hline
\end{tabular}

Similar to Taguchi's method, here also three different approaches - 'the larger the better', 'the smaller the better', and, 'the nominal the better' is used as calculated by equations 5 and 6 .

$$
\begin{aligned}
X,(k) & =\frac{y_{i(k)-\operatorname{miny}_{i(k)}}}{\operatorname{maxy}_{i(k)-\operatorname{miny}_{i(k)}}} \\
X i(k) & =\frac{\operatorname{maxy}_{i(k)-y_{i(k)}}}{\operatorname{maxy}_{i(k)-\operatorname{miny}_{i(k)}}}
\end{aligned}
$$

Where $\mathrm{Xi}(\mathrm{k})$ is the value after generation of grey relation, Max $\mathrm{yi}(\mathrm{k})$ and $\operatorname{Min} \mathrm{yi}(\mathrm{k})$ are the largest and the smallest value of yi $(\mathrm{k})$ for the $\mathrm{k}_{\mathrm{th}}$ response, respectively. After data generation, grey relation coefficient and grey relation grade were calculated which are shown in Table 6. Response table provides the optimum parametric combination for the best machining response and performance characteristics. Table 7 shows the grey relation response of the input parameters. A maximum value of each parameter out of the three levels shows the optimum level of machining. From the table 7 , optimum machining condition can be found to be $\mathrm{A}_{1}, \mathrm{~B}_{3}, \mathrm{C}_{1}, \mathrm{D}_{1}$ with corresponding values are peak current $2 \mathrm{Amp}, \mathrm{T}_{\text {on }} 25$ $\mu \mathrm{s}, \%, \mathrm{~T}_{\text {off }} 3 \mu \mathrm{s}$, and, wire feed $8 \mathrm{~mm} / \mathrm{min}$. Table 8 shows a comparative study of both the optimization techniques Taguchi's $\mathrm{L}_{27}$ array and grey relation analysis. Results obtained in the table show that a $3.80 \%$ improvement in the surface finish could be achieved with machining through the optimum condition of grey relation analysis. Metal removal rate was also improved by $12.02 \%$ with the grey relation parameters. 
Table 7: Grey Relation Response Table

\begin{tabular}{|c|c|c|c|c|}
\hline \multicolumn{5}{|c|}{ Input Parameters } \\
\hline Level & A-Peak Current & B-T $_{\text {ON }}$ & C-T $_{\text {OFF }}$ & D-Wire Feed \\
\hline level 1 & $\mathbf{0 . 6 2 3}$ & 0.5757 & $\mathbf{0 . 6 5 3 9}$ & $\mathbf{0 . 5 6 1 6}$ \\
\hline level2 & 0.507 & 0.519 & 0.5037 & 0.5503 \\
\hline level 3 & 0.5409 & $\mathbf{0 . 5 7 6 1}$ & 0.5133 & 0.5589 \\
\hline
\end{tabular}

Table 8: Comparison of Confirmation Experiment

\begin{tabular}{|c|c|c|c|c|c|c|c|c|}
\hline $\begin{array}{c}\text { Method of } \\
\text { Optimization } \\
\text { Process }\end{array}$ & $\begin{array}{c}\text { Output } \\
\text { Response }\end{array}$ & $\begin{array}{c}\text { Input } \\
\text { Parameter }\end{array}$ & $\mathbf{A}$ & B & $\mathbf{C}$ & D & $\begin{array}{c}\text { Machining } \\
\text { Output } \\
\text { Response }\end{array}$ & $\begin{array}{c}\% \\
\text { Change }\end{array}$ \\
\hline \multirow{2}{*}{$\begin{array}{l}\text { Taguchi's } \mathbf{L}_{27} \\
\text { array }\end{array}$} & Surface Roughness & Level & $\mathrm{A}_{1}=2$ & $\mathrm{~B}_{1}=15$ & $\mathrm{C}_{2}=4$ & $D_{3}=9$ & 2.18 & --- \\
\hline & MRR & Level & $\mathrm{A}_{3}=4$ & $\mathrm{~B}_{3}=25$ & $\mathrm{C}_{3}=5$ & $\mathrm{D}_{1}=8$ & 1.654 & ---- \\
\hline \multirow{2}{*}{$\begin{array}{l}\text { Grey relation } \\
\text { analysis }\end{array}$} & Surface Roughness & \multirow{2}{*}{\multicolumn{5}{|c|}{$A_{1}=2, B_{3}=25, C_{1}=3, D_{1}=8$}} & 2.1 & $3.80 \%$ \\
\hline & MRR & & & & & & 1.8 & $12.02 \%$ \\
\hline
\end{tabular}

\section{CONCLUSIONS}

During the wire EDM process of the hybrid MMC and optimization of the machining parameters through Taguchi's technique and grey relation analysis, the following conclusions could be listed:

- Peak current is the most significant factor which drastically affects surface roughness and MRR with a contribution of $70.03 \%$ and $66.76 \%$, respectively.

- The optimized values for surface roughness and MRR attained through Taguchi's confirmation experiment, are $2.18 \mu$ mand $1.654 \mathrm{~mm} / \mathrm{min}$ respectively.

- The R-Squared values calculated through Taguchi's technique for surface roughness and MRR are 0.9923and 0.9738 respectively which confirms the accuracy of the intended constants and fitness of the developed model.

- The optimum set of machining parameters from Grey relation analysis is $\mathrm{A}_{1}, \mathrm{~B}_{3}, \mathrm{C}_{1}, \mathrm{D}_{1}$, for performance evaluation of all the two output responses, namely, surface roughness and MRR.

- The optimized values of surface roughness and MRR attained through grey relation confirmation experiment are $2.1 \mu \mathrm{m}$ and $1.80 \mathrm{~mm} / \mathrm{min}$ respectively.

- While comparing the results of Taguchi's technique and grey relation analysis, surface roughness and MRR values discovered through grey relation analysis at $3.80 \%$ and $12.02 \%$, respectively can be found to be much better as compared to Taguchi's experiment.

\section{REFERENCES}

1. Srivastava, A. K., Dixit, A. R., \& Tiwari, S. (2016). Investigation of micro-structural and mechanical properties of metal matrix composite A359/B ${ }_{4}$ C through electromagnetic stir casting,2016, 23, 171-180.

2. Srivastava, A.R. Dixit, S. Tiwari, Experimental Investigation of Wire EDM Process Parameteres on Aluminum Metal Matrix Composite Al2024/SiC, Int. J. Adv. Res. Innov. 2 (2014) 511-515.

3. Mardi KB, Dixit AR, Srivastava AK, Mallick A, J. Scucka, P. Hlavacek, S. Hloch, M. Zelenak, Effect of Water Pressure During Abrasive Waterjet Machining of Mg-Based Nanocomposite. In: Singh M., Kushvah B., Seth G., Prakash J. (eds) Applications of Fluid Dynamics. Lecture Notes in Mechanical Engineering. Springer, Singapore, 
https://doi.org/10.1007/978-981-10-5329-0_46.

4. Babu N. Hari, Tzamtzis S., Barekar N., Patel J. B. and Fan Z., (2008), Fabrication of Metal Matrix Composites under Intensive Shearing, Solid State Phenomena,141-143, 373-378.

5. AK Srivastava, AR Dixit, S Tiwari, A Review on intensification of metal matrix composites and its non-conventional machining, Sci. Eng. of Compos. Mater, (2016), DOI: https:// doi. Org/ 10.1515/secm-2015-0287.

6. A.K. Srivastava, A. Nag, A.R. Dixit, S. Tiwari, J. Scucka, M. Zelenak, S. Hloch, P. Hlavacek, Surface integrity in tangential turning of hybrid MMC A359/B 4 C/Al 2 O 3 by abrasive waterjet, J. Manuf. Process. 28 (2017) 11-20.

7. Garg H. K., Verma K., Manna A., Kumar R., (2012), Hybrid Metal Matrix Composites and further improvement in their machinability- A Review, International Journal of Latest Research in Science and Technology, 1(1), 36-44.

8. Srivastava A.K., Nag A., Dixit A.R., Tiwari S., Srivastava V.S. (2019) Parametric Study During Abrasive Water Jet Turning of Hybrid Metal Matrix Composite. In: Hloch S., Klichová D., Krolczyk G., Chattopadhyaya S., Ruppenthalová L. (eds) Advances in Manufacturing Engineering and Materials. Lecture Notes in Mechanical Engineering. Springer, Cham, https://doi.org/10.1007/978-3-319-99353-9 9.

9. Nag A, Srivastava AK, Dixit AR, Chattopadhyaya S, Mandal A, P. Hlavacek, D. Klichova M. Zelenak, S. Hloch, Influence of Abrasive Water Jet Turning Parameters on Variation of Diameter of Hybrid Metal Matrix Composite. In: Singh M., Kushvah B., Seth G., Prakash J. (eds) Applications of Fluid Dynamics. Lecture Notes in Mechanical Engineering. Springer, Singapore https://doi.org/10.1007/978-981-10-5329-0_36

10. F. Muller and J. Monaghan, (2000), Non-conventional machining of particle reinforced metal matrix composite, International Journal of Machine Tools \& Manufacture, (40), 1351-1366.

11. S. S. Mahapatra \&Amar P., (2007), Optimization of wire electrical discharge machining (WEDM) process parameters using Taguchi method, International Journal of Advance Manufacturing Technology, 34(9-10), 911-925.

12. K. Kanlayasiri, S. Boonmung, (2007), Effects of wire-EDM machining variables on surface roughness of newly developed DC 53 die steel: Design of experiments and regression model, Journal of Materials Processing Technology, (192-193), 459-464.

13. M. Boujelbene, E. Bayraktar, W. Tebni, S. Ben Salem, (2009), Influence of machining parameters on the surface integrity in electrical discharge machining, Archives of Materials Science and Engineering, 37(2), 110-116.

14. Anil Kumar, S. Maheshwari, C. Sharma, Naveen Beri (2010), A Study of Multi objective Parametric Optimization of Silicon Abrasive Mixed Electrical Discharge Machining of Tool Steel, Materials and Manufacturing Processes,25(10),1041-1047.

15. Kapil Kumar and Sanjay Agarwal, (2012), Multi-objective parametric optimization on machining with wire electric discharge machining, International Journal of Advance Manufacturing Technology, (62) 617-633.

16. B. Jabbaripour, M. H. Sadeghi, Sh. Faridvand M. R. Shabgard, (2012), Investigating the effects of EDM Parameters on Surface Integrity, MRR and TWR in machining of Ti-6Al-4V, Machining Science and Technology: An International Journal, $16(3), 419-444$.

17. D Sudhakara, B Venkataramana Naik, B Sreenivasulu, (2012), The experimental analysis of surface characteristics of Inconel718 using Electrical discharge machining, International Journal of Mechanical Engineering\& Robotics Research, (1), 371388.

18. Garg H. K., Verma Ketan, Manna Alakesh and Kumar Rajesh, (2012), Hybrid Metal Matrix Composites and further improvement in their machinability- A Review, International Journal of Latest Research in Science and Technology, 1(1), 3644. 
19. S. S. Baraskar, S. S. Banwait, S. C. Laroiya, (2013), Multiobjective Optimization of Electrical Discharge Machining Process Using a Hybrid Method, Materials and Manufacturing Processes, 28(4), 348-354.

20. A.K. Srivastava, A. Nag, A.R. Dixit, S. Hloch, S. Tiwari, J. Scucka, P. Pachauri, Surface integrity in wire-EDM tangential turning of in-situ hybrid metal matrix composite A359/B ${ }_{4} C / \mathrm{Al}_{2} \mathrm{O}_{3}$, Sci. Eng. Compos. Mater. (2018), 10.1515/secm-2017-0391.

21. Malaquias, J. V., Celestino, S. M. C., \& Xavier, M. F. F. (2018). Optimization of the roasting conditions of arabica coffee cultivated in the cerrado area of Brazil. Brazilian Journal of Food Technology, 21.

22. Ashish Kumar Srivastava, Akash Nag, Amit Rai Dixit, Jiri Scucka, Sergej Hloch, Dagmar Klichová, PetrHlaváček, SandeepTiwari, Hardness measurement of surfaces on hybrid metal matrix composite created by turning using an abrasive water jet and WED, Measurement,2019, 131, pp 628-639.

23. Nag, J. Šččcka, P. Hlavacek, D. Klichová, A.K. Srivastava, S. Hloch, A.R. Dixit, J. Foldyna, M. Zelenak, Hybrid aluminium matrix composite AWJ turning using olivine and Barton garnet, Int. J. Adv. Manuf. Technol. (2017) 1-8. 